\title{
Crystal structure of hexamethanolo-iron diiodide, $\mathrm{Fe}\left(\mathrm{HOCH}_{3}\right)_{6} \mathbf{I}_{2}$
}

\author{
Klaus Harms, Frank Biesemeier and Ulrich Müller* \\ Universität Marburg, Fachbereich Chemie, D-35032 Marburg, Germany
}

Received March 3, 2003, accepted and available on-line May 7, 2003; CSD-No. 409697

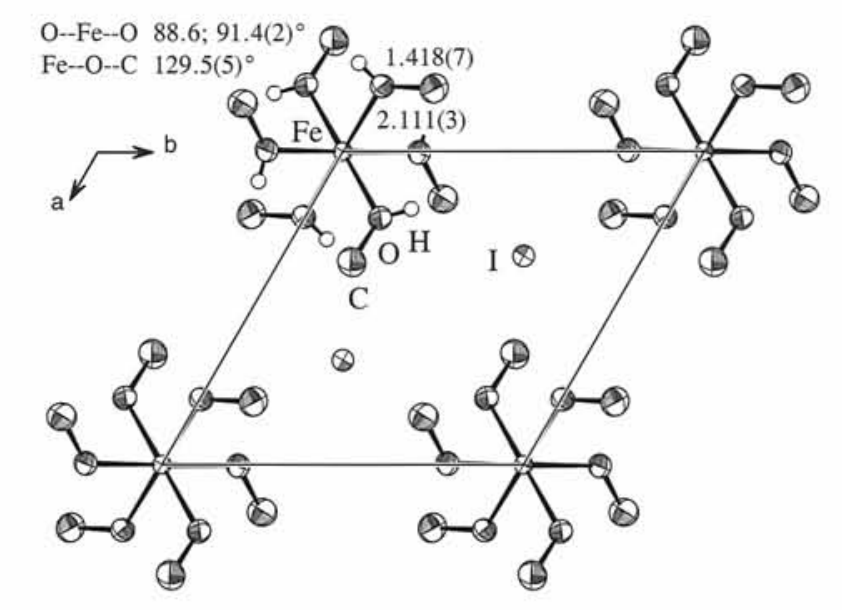

Abstract

$\mathrm{C}_{6} \mathrm{H}_{24} \mathrm{FeI}_{2} \mathrm{O}_{6}$, trigonal, $\bar{P}$ (No. 147), $a=8.2947(8) \AA, c=7.0884(6) \AA$, $V=422.4 \AA^{3}, Z=1, R_{\mathrm{gt}}(F)=0.023, w R_{\mathrm{ref}}\left(F^{2}\right)=0.065, T=193 \mathrm{~K}$.

\section{Source of material}

Iron diiodide $(0.31 \mathrm{~g})$, prepared from iron and iodine [1], was dissolved in $2.0 \mathrm{~mL}$ of anhydrous methanol. After addition of $10 \mathrm{~mL}$ of anhydrous diethylether the title compound crystallized in the course of two hours. After decantation the crystals were dried in a stream of dry argon.

\section{Experimental details}

$\mathrm{Fe}\left(\mathrm{HOCH}_{3}\right)_{6} \mathrm{I}_{2}$ is isotypic to $\mathrm{Ca}\left(\mathrm{HOCH}_{3}\right)_{6} \mathrm{Br}_{2}$ [2]. As noted for the latter, merohedral twinning occurs. However, contrary to [2], we do not find (001) as a twinning plane, but twins of twins with the twinning planes (110) and (120). The domains of the (120)-twinning are very small, as evidenced by the refinement results: assuming macroscopic twinning along (120) (superposition of $F^{2}$ values) resulted in $R_{\mathrm{gt}}(F)=0.035$; superposition of $F$ values yielded $R_{\mathrm{gt}}(F)=0.023$. However, for another crystal the $F^{2}$ superposition was slightly better. The four components of the reported crystal had volume fractions of $0.61(1), 0.13$ (110)-twin, 0.22 (120) and 0.04 (210). If all four components had the same volume fractions, their superposition would feign the space group $P 6 / \mathrm{mmm}$, which is a supergroup of $P \overline{3}$.

\section{Discussion}

The methyl groups and iodide ions are arranged like in a hexagonal closest-packing. One eighth of the octahedral voids are occupied by $\mathrm{Fe}^{2+}$ ions together with the $\mathrm{O}$ atoms linking them to the methyl groups. Another description relates the structure to the $\mathrm{CdI}_{2}$ type, in which $\mathrm{Fe}\left(\mathrm{OCH}_{3}\right)_{6}{ }^{2+}$ ions take the positions of the cadmium ions.

Table 1. Data collection and handling.

\begin{tabular}{ll}
\hline Crystal: & $\begin{array}{l}\text { colourless hexagonal prism, } \\
\text { size } 0.13 \times 0.24 \times 0.34 \mathrm{~mm}\end{array}$ \\
Wavelength: & Mo $K_{\alpha}$ radiation $(0.71073 \AA)$ \\
$\mu:$ & $45.61 \mathrm{~cm}^{-1}$ \\
Diffractometer, scan mode: & Stoe IPDS $2 ; \Delta \varphi=1^{\circ}, \omega=0^{\circ}-180^{\circ}$ at $\varphi=$ \\
& $30^{\circ}, \omega=0^{\circ}-98^{\circ}$ at $\varphi=120^{\circ}$ \\
$2 \theta_{\text {max }}:$ & $57.26^{\circ}$ \\
$N(h k l)_{\text {measured }}, N(h k l)_{\text {unique }}:$ & 5978,730 \\
Criterion for $I_{\text {obs }}, N(h k l)$ gt: & $I_{\text {obs }}>2 \sigma\left(I_{\text {obs }}\right), 726$ \\
$N(\text { param })_{\text {refined: }}$ & 37 \\
Program: & SHELX-97 [3] \\
& \\
\hline
\end{tabular}

Table 2. Atomic coordinates and displacement parameters (in $\AA^{2}$ ).

\begin{tabular}{llllll}
\hline Atom & Site & $x$ & $y$ & $z$ & $U_{\text {iso }}$ \\
\hline $\mathrm{H}(1)$ & $6 g$ & $0.19(1)$ & $0.28(1)$ & $0.20(1)$ & $0.04(2)$ \\
$\mathrm{H}(2)$ & $6 g$ & 0.4335 & 0.3229 & 0.3337 & 0.16 \\
$\mathrm{H}(3)$ & $6 g$ & 0.4297 & 0.1717 & 0.1905 & 0.16 \\
$\mathrm{H}(4)$ & $6 g$ & 0.2967 & 0.1055 & 0.3717 & 0.16 \\
\hline
\end{tabular}

\section{References}

1. Brauer, G.: Handbuch der präparativen anorganischen Chemie, 3. Aufl.,p. 1644. F. Enke, Stuttgart 1981.

2. Halut-Desportes, S.; Philoche-Levisaller, M.: Structures comparés des solvates de formule $\mathrm{MBr}_{2} \cdot 6 \mathrm{CH}_{3} \mathrm{OH}$. Acta Crystallogr. B34 (1978) 432-435.

3. Sheldrick, G. M.: SHELX-97. A program package for crystal structure solution and refinement, University of Göttingen, Germany 1997.

Table 3. Atomic coordinates and displacement parameters (in $\AA^{2}$ ).

\begin{tabular}{lllllllllll}
\hline Atom & Site & $x$ & $y$ & $z$ & $U_{11}$ & $U_{22}$ & $U_{33}$ & $U_{12}$ & $U_{13}$ & $U_{23}$ \\
\hline $\mathrm{Fe}$ & $1 a$ & 0 & 0 & 0 & $0.0196(3)$ & $U_{11}$ & $0.0294(6)$ & $U_{11} / 2$ & 0 & 0 \\
$\mathrm{I}$ & $2 d$ & $1 / 3$ & $2 / 3$ & $0.23363(7)$ & $0.0259(2)$ & $U_{11}$ & $0.0450(2)$ & $U_{11} / 2$ & 0 & 0 \\
$\mathrm{O}$ & $6 g$ & $0.2127(5)$ & $0.2083(5)$ & $0.1675(6)$ & $0.033(2)$ & $0.024(2)$ & $0.050(2)$ & $0.016(1)$ & $-0.017(2)$ & $-0.010(2)$ \\
$\mathrm{C}$ & $6 g$ & $0.3541(8)$ & $0.202(1)$ & $0.2741(8)$ & $0.043(4)$ & $0.045(3)$ & $0.056(4)$ & $0.022(3)$ & $-0.029(3)$ & $-0.009(3)$ \\
\hline
\end{tabular}

\footnotetext{
* Correspondence author (e-mail:mueller@ chemie.uni-marburg.de)
} 